NBER WORKING PAPER SERIES

\title{
DO HUMANS SUFFER A PSYCHOLOGICAL LOW IN MIDLIFE? TWO APPROACHES (WITH AND WITHOUT CONTROLS) IN SEVEN DATA SETS.
}

\author{
David G. Blanchflower \\ Andrew Oswald \\ Working Paper 23724 \\ http://www.nber.org/papers/w23724 \\ NATIONAL BUREAU OF ECONOMIC RESEARCH \\ 1050 Massachusetts Avenue \\ Cambridge, MA 02138 \\ August 2017
}

The views expressed herein are those of the authors and do not necessarily reflect the views of the National Bureau of Economic Research.

At least one co-author has disclosed a financial relationship of potential relevance for this research. Further information is available online at http://www.nber.org/papers/w23724.ack

NBER working papers are circulated for discussion and comment purposes. They have not been peer-reviewed or been subject to the review by the NBER Board of Directors that accompanies official NBER publications.

(C) 2017 by David G. Blanchflower and Andrew Oswald. All rights reserved. Short sections of text, not to exceed two paragraphs, may be quoted without explicit permission provided that full credit, including $\odot$ notice, is given to the source. 
Do Humans Suffer a Psychological Low in Midlife? Two Approaches (With and Without

Controls) in Seven Data Sets.

David G. Blanchflower and Andrew Oswald

NBER Working Paper No. 23724

August 2017

JEL No. I3

\begin{abstract}
$\underline{\text { ABSTRACT }}$
Using seven recent data sets, covering 51 countries and 1.3 million randomly sampled people, the paper examines the pattern of psychological well-being from approximately age 20 to age 90 . Two conceptual approaches to this issue are possible. Despite what has been argued in the literature, neither is the 'correct' one, because they measure different things. One studies raw numbers on well-being and age. This is the descriptive approach. The second studies the patterns in regression equations for well-being (that is, adjusting for other influences). This is the ceteris-paribus analytical approach. The paper applies each to large cross-sections and compares the patterns of life-satisfaction and happiness. Using the first method, there is evidence of a midlife low in five of the seven data sets. Using the second method, all seven data sets produce evidence consistent with a midlife low. The scientific explanation for the approximate U-shape currently remains unknown.
\end{abstract}

David G. Blanchflower

Bruce V. Rauner Professor of Economics

6106 Rockefeller Hall

Dartmouth College

Hanover, NH 03755-3514

and NBER

David.G.Blanchflower@Dartmouth.EDU

Andrew Oswald

Department of Economics

and also CAGE Research Center

University of Warwick

Coventry CV4 7AL

England

a.j.oswald@warwick.ac.uk 
Do Humans Suffer a Psychological Low in Midlife? Two Approaches (With and Without Controls) in Seven Data Sets

"Life satisfaction is stable across... age groups."

Diener et al. (1999)

\section{Introduction}

What is the pattern of mental well-being at different ages in the human life-course? This important question is relevant to scientific researchers across a wide range of disciplines. Nearly two decades ago, Diener, Suh, Lucas, and Smith (1999) concluded that well-being and quality of life are essentially independent of age. They illustrated that view with a flat line (in their Figure 3). Monographs at that time, such as Argyle (2001), were typically similar. To our knowledge, most textbooks in social psychology continue to teach students the same result.

How should this important topic be studied by economists and behavioural scientists? One way to tackle the question is to use longitudinal data sets in which different sorts of people are followed throughout their lives. This has many advantages. It also has the potential disadvantage that, at the time of writing, such data sets tend to be fairly small and not to extend over a long span of adult life. Moreover, some human beings may become disenchanted with being interviewed and, in a free country, cannot be forced to stay in a longitudinal sample. Those who drop out of a longitudinal survey may not do so randomly. If such attrition is then biased, in ways that are important to an investigator's inquiry, the patterns observed in the remaining sample of individuals will give misleading answers. ${ }^{1}$

Another way to study such a question is to use cross-sectional data sets. This is a snapshot approach (to use the term adopted in Stone et al. 2010). It has some advantages, including

\footnotetext{
${ }^{1}$ As a related example that is topical at the time of writing, the longitudinal British Election Study Wave 9 asked UK respondents after the EU referendum on Brexit how they voted. In the survey a small majority of the respondents reported that they voted to leave - by a margin of $49.5 \%$ to $50.5 \%$ for remain. This contrasted with the actual outcome of $51.9 \%$ for Leave. The head of the BES Professor Ed Fieldhouse told us in private communication that "this is because a known bias in the sample which is that politically interested people are more likely to respond/remain in the study."
} 
simplicity, and the ability to examine large cross-national samples. It has the disadvantages that it may be subject to year-of-birth cohort effects and that, more broadly, the statistical information about ageing then comes from cross-person rather that within-person observation. Such cohort effects are themselves, in principle, of scientific interest.

This paper argues that the traditional Diener et al. (1999) wellbeing-is-flat-through-life conclusion does not do justice to current evidence. We examine data on 1.3 million randomly sampled individuals across a large number of nations. The paper brings together seven crosssectional data sets, treats them in a statistically consistent way, and plots the results. It implicitly argues that it is natural for researchers to try to understand the patterns in pooled cross-sectional data sets as well as those in longitudinal data set sets.

The background literature is large and, currently, a shade disputatious (Baird et al. 2010, Blanchflower and Oswald 2008, Carstensen et al. 2011, Charles et al. 2001, Easterlin 2003, 2006, Frey and Stutzer 2002, Frijters and Beaton 2012, Glenn 2009, Graham and Pozuelo 2017, Hellevik 2017, Hudson et al. 2016, Lachman 2015, Mroczek and Kolanz 1998, Mroczek and Spiro 2005, Shields and Wheatley Price 2005, Stone et al. 2010, Steptoe et al. 2015, Wunder et al. 2013, Schwandt 2016). Helliwell and Grover (2014) argue that married people have a slightly shallower U-shape dip than the unmarried. An unusual paper that is related to this literature, which uses data on three samples of great apes, also documents evidence of a $U$ shape: Weiss et al. (2012).

Easterlin (2006) is a particularly important paper. Controlling for year of birth, the paper finds evidence of a hill-shape in well-being over the life cycle. It uses pooled General Social Survey data from the United States. Richard Easterlin's paper is one of a number of challenges to the early Diener et al. (1999) result. Debate in this area has recently been fierce. A modern review by Ulloa et al. (2013) goes as far as to draw the conclusion that "extant studies ... show either a U-shaped, inverted U-shaped or linear relation between ageing and subjective well- 
being." Other studies, such as Lachman (2015), come close to arguing that there may be a midlife dip but that it may be too small to be significant.

\section{Analysis}

Within the cross-section tradition, two broad ways to analyze the paper's scientific issue can be found in the literature. Despite what is sometimes argued (such as in Glenn 2009 and Hellevik 2017), it is not natural to see either approach as the 'right' or 'wrong' one. The reason is that they measure different things.

One set of writings has attempted to study raw numbers on well-being and age. This might be called the descriptive approach. A second, including Blanchflower and Oswald (2008), has examined the patterns in regression equations for well-being (that is, adjusting for other influences). This might be termed the ceteris-paribus analytical approach. Methods of the latter kind are standard in epidemiology and economics, for example, where the tradition has been to try to understand the consequences of an independent variable (smoking, income, etc) after adjusting for other influences on the dependent variable.

The descriptive approach measures the 'total', or reduced-form, effect of age. By contrast, the ceteris-paribus analytical approach measures the marginal effect of age after controlling for other socio-economic influences. For example, as people move from their 20 s to their 50 s, they typically become considerably richer. Say, for illustrative purposes, they also become happier. The descriptive approach would then ascribe the possible rise in their happiness over that period as due to age. The analytical approach would divide the possible rise in happiness into two components - that coming from income per se and any residual effect from ageing per se. In principle, neither of these approaches is better than the other. Which is the more appropriate, in a particular empirical setting, will depend on the exact research question being addressed by the investigator.

The paper's later analysis is an attempt to compare these two. It looks at: 
- Estimates of the well-being-age relationship both with and without adjustments for the other influences on well-being;

- Samples of adults up to the age of 90 (after which extreme ill-health becomes prevalent: we are doubtful that many researchers believe that humans are happy in the final few years of life: Evidence is provided by Gerstorf et al. 2010);

- Estimates that do not adjust for people's incomes (that is, it is not one of the controls), partly to be comparable with most of the literature, and partly because in some of the seven data sets there are no data on earnings;

- Statistical analysis that uses a set of individual age-year dummy variables (more than 70 individual dummy variables), to ensure that the data are able to follow any pattern, so that no particular mathematical form is artificially forced on the data.

It will become apparent below that the well-known papers of Easterlin (2006) and Glenn (2009), which are sometimes taken as key ones that shed doubt on the idea of a midlife low, rely on the one data set out of the seven that is rather unrepresentative of patterns in others.

Analogously, there is also evidence that there is an inverted U-shape in unhappiness. Blanchflower and Oswald (2008), for example showed such a pattern in depression data for the UK, which maximized at around age 45. At the time of writing we also became aware of a recent Office for National Statistics publication for England and Wales which showed that drug poisoning deaths maximized at ages 40-49..$^{2}$ This age group had a mortality rate of 108.0 in 2016, versus in that year a rate of 43.7 for ages 20-29; a rate of 97.5 for ages $30-39$; a rate of 39.4 for $50-69$, and a rate of 10.7 for 70 and older. There is some evidence that the maximum had recently moved up. In 2015, the age 30-39 group had the highest rate. This arose because

\footnotetext{
2 'Deaths related to drug poisoning in England and Wales: 2016 registrations', ONS, $2^{\text {nd }}$ August 2017 https://www.ons.gov.uk/peoplepopulationandcommunity/birthsdeathsandmarriages/deaths/bulletins/deathsrelate dtodrugpoisoninginenglandandwales/2016registrations
} 
of a large increase for the 40-49 year olds' mortality rate from 95.1 in 2015 compared with a fall for the 30-30 group whose 2015 rate was 98.4 .

The current paper's seven data sets provide information on more than one million randomly sampled citizens; each person is asked questions about happiness or life satisfaction. These data sets are, respectively, for the United Kingdom, the USA, 36 European countries, 32 European countries, 51 nations around the world, and (again) the USA. We take each in turn, and begin with two data sets collected by official government statistical agencies (the UK Office of National Statistics and the US Centres for Disease Control) in which the random sampling is presumably of reliable quality.

\section{UK (Office for National Statistics data)}

Figure 1 plots life-satisfaction data for approximately 416,000 randomly sampled citizens of the United Kingdom. Well-being data are now collected annually as part of official government statistics by the UK Office for National Statistics (ONS). One of those is a measure of citizens' overall life satisfaction. The details and sampling methods are discussed at website www.ons.gov.uk/well-being.

Figure 1, and each of the later figures in this paper, lays out two kinds of plots. One is for raw averaged life-satisfaction scores at different ages. This is the descriptive approach, advocated by, for example, Glenn (2009). The other, derived from a regression equation in which other covariates (so-called 'controls') are included, is the regression-adjusted level of life-satisfaction. This can be thought of as an estimate of the pure or 'marginal' effect of ageing. It can be seen in the Figure that the two curves are similar to one another, so in this case the adjustment for controls does not greatly affect the fundamental conclusions.

What comes out of Figure 1 is a broad, and perhaps surprisingly smooth, pattern. Wellbeing starts high in youth; it then declines reasonably steadily (apart from a blip around the 
mid-20s) until approximately the age of 50; it then rises in a hill-like way up to approximately the age of 70; after that it declines slightly until the age of 90.

The covariate controls in this case are gender, race, level of education, marital status, labor market status, region within the UK, and year dummies. The exact sample size is 415 , 589 and covers the years 2011 to 2015 inclusive.

\section{USA (BRFSS data)}

Figure 2 plots life-satisfaction data for approximately 427,000 randomly sampled citizens of the USA. The data are from the Behavioral Factor Surveillance System, which is a survey run by the US Centres for Disease Control, available through www.cds.gov/brfss. The data are for 2010, which is the most recent year in which the BRFSS asked this question. As before, the Figure lays out two kinds of plots. One is for raw averaged life-satisfaction scores at different ages. The other, derived from a regression equation in which other covariates (socalled 'controls') are included, is the regression-adjusted level of life-satisfaction. It can be seen, as in Figure 1 for UK data, that the two curves in Figure 2 have some similarities to one another. There is apparently some form of midlife low, although now the adjusted nadir (that is, with controls) is closer to early-40s rather than approximately 50. However, the pattern across all ages in the no-controls case is more 'wavy' with an early dip at the start of people's 20s. Adjusted well-being in the USA starts high in youth, declines smoothly until the flat part in middle age; it then rises in hill-like way to approximately the age of 70; after that it runs roughly flat, or even fractionally up, until the age of 90.

The controls in this case are gender, race, level of education, marital status, labor market status, disability dummy variable, number of children, and dummy variables for the state the person lives in within the US. The exact sample size is 426, 648 .

\section{Europe (Eurobarometer data)}


Figure 3 plots life-satisfaction data for approximately 32,000 randomly sampled citizens across a pooled set of 36 Europeans. The data are from the Eurobarometer Survey series, available through www.ec.europa.eu. Figure 3 has the previous form of double plot. One is for raw averaged life-satisfaction scores at different ages. The other is the regressionadjusted level of life-satisfaction. As in Figure 1 for the UK, and to less extent in Figure 2 for the USA, the two curves track each other. Thus, as before, in this case the adjustment for controls does not alter the fundamental result.

What comes out of Figure 3 is a pattern very like the one in Figure 1. Well-being starts high in youth; it falls in a fairly linear way to approximately the mid-50s; as an underlying trend, it then rises in a roughly linear way up to approximately the age of 90 . The controls in this case are country dummy variables, gender, level of education, marital status, labor market status, and year dummies. The exact sample size is 32,857 and is for the year 2016 .

\section{Europe (ESS data)}

Using a different data set, Figure 4 plots happiness data for approximately 316,000 randomly sampled Europeans. Here the data are from the European Social Survey, available from www.europeansocialsurvey.org. One curve is for raw averaged happiness scores at different ages. The other allows for controls in the equation for happiness. It can be seen in the Figure that the two curves have elements in common. However, allowing for controls gives a more pronounced V shape. Nevertheless, in both of the shapes within Figure 4, well-being starts high in youth; it then drops until approximately the early 50; it then goes up quite strongly in the adjusted case and rather mildly in the raw-data case. The controls in the ESS regression are gender, level of education, marital status, labor market status, country dummy variables, and year dummies. The exact sample size is 316, 509 and covers years 2002 to 2014 inclusive.

\section{Multi-country (ISSP data)}


Figure 5 plots happiness data for just over 59,000 randomly sampled citizens from 45 nations of the world. The data come from the International Social Survey Program, available through www.issp.org, and the 41 countries are as follows (Argentina, Australia, Austria, Belgium, Bulgaria, Canada, Chile, China, Taiwan, Croatia, Czech Republic, Denmark, Finland, France, Germany, Hungary, Iceland, N-India, Ireland, Israel, Japan, South Korea (South), Latvia, Lithuania, Mexico, Netherlands, Norway, Philippines, Poland, Portugal, Russia, Slovakia, Slovenia, South Africa, Spain, Sweden, Switzerland, Turkey, United Kingdom, United States and Venezuela). Here the unadjusted curve takes a slightly different form: it falls in the usual way until around age 50, but then it runs essentially flat into older age. Despite the evident irregularities, it can be seen in the case with controls that, once more, well-being starts high in youth; it then declines fairly systematically until approximately the age of 50; from then on it rises in a reasonably linear way up to approximately the late 80 s. The controls in this case are country dummies, gender, years of education, marital status, and labor market status. The exact sample size is 59,156 and is for the year 2012 .

\section{USA (GSS data)}

The sixth data set is described in Figure 6. It plots happiness data for approximately 54,000 randomly sampled citizens of the USA. The data are from the long-running General Social Survey of the United States, available at www.gss.norc.org.

In Figure 6, there is a marked difference in shape between the adjusted and unadjusted curves. In the no-controls case, there is almost no sign of a $U$ shape. Instead, the data are more consistent with a flat line (with uneven jumps in it). However, what emerges from Figure 6 once controls are allowed for is a version of a more familiar pattern. There is some sign of a U shape (of a shallow kind) and then a climb up in well-being from approximately the early 50s until the early 70s, after which the trend is nearly flat. The controls in this case are gender, 
race, level of education, marital status, labor market status, and year dummies. The exact sample size is 54,532 and covers the years 1972 to 2014 inclusive.

\section{Multi-country (Latino Barometer data)}

Figure 7 plots life satisfaction data for approximately 43,000 randomly sampled citizens from 18 Latin American nations of the world. The data come from the Latino Barometer Program, available through www.latinobarometro.org, and the 18 countries are Argentina, Bolivia, Brazil, Canada, Chile, Colombia, Costa Rica, Dominican Republic, Ecuador, El Salvador, Guatemala, Honduras, Mexico, Nicaragua, Panama, Paraguay, Peru and Venezuela.

Here the unadjusted curve takes a broadly U-shaped, but slightly irregular, form: it falls in the usual way until midlife, and rises somewhat jerkily into older age. It can be seen in the case with controls that once more well-being starts high in youth; after that it declines; the pattern then rises in a nonlinear way up to approximately the late $80 \mathrm{~s}$.

The controls in this case are country dummies, gender, years of education, marital status, and labour market status. The sample size is 42,913 and covers years 2013 and 2015.

\section{Discussion}

Five points seem relevant. First, it is natural to emphasize that, as in most writings in the literature, the data used in this paper are cross-sectional. It might be argued that longitudinal data are, in principle, the desirable kind of testbed. How serious a concern is that? A well-known early paper by Mroczec and Spiro (2005) concludes that well-being is humpshaped in age, and is thus sometimes quoted as longitudinal evidence against a $U$ pattern, but in fact its data begins from midlife, so an initial rise might be expected. There is a correction for cohort effects in Blanchflower and Oswald (2008), and there are emerging panel results, such as Cheng et al. (2017), in which in four longitudinal data sets a U shape is found. Perhaps the most effective longitudinal evidence against a midlife low is the potentially important work 
of Galambos, Fang, Krahn, Johnson, Lachman (2015) on Canadian data. It is not currently possible to know why the small number of modern longitudinal studies do not currently agree with one another.

However, there is an important case to be made against the sole use of longitudinal data. What has not often been pointed out in the literature is that longitudinal data sets have a drawback. They face the problem of non-random attrition. In the case of Galambos et al. (2015), for example, half of the sample drop out through time in the study. It remains an open question whether that allows reliable inferences to be drawn (if, as seems plausible, unhappy people decline to answer survey questionnaires, for example).

Moreover, there remains the intriguing intellectual question: why do so many pooled cross-section data sets produce a U shape? It therefore seems appropriate to treat large crosssectional samples, of the sort used in this paper's analysis, as offering one form of evidence that will eventually have to be understood.

Second, perhaps the midlife decline is substantively tiny, even if statistically significant? If so, the data can in practice be viewed as approximately flat through the course of life. That view does not appear to be correct. In our seven data sets, as explained in the Figures, the size of the drop in well-being to the low point in the late $40 \mathrm{~s}$ is equivalent in magnitude to the influence of a major life event like unemployment or marital separation.

Third, it might be argued, as by Glenn (2009), that it is inappropriate to include covariate controls. It is hard to see why that methodological position -- one that is the opposite of standard practice in some disciplines -- is an inevitable one (the issues is discussed in Blanchflower and Oswald, 2009). In general, scientific researchers do not wish solely to describe the patterns that are observed in the world. This paper suggests that two approaches -- descriptive and analytical -- are possible, that neither is the right one, and that both have their place and, ultimately, have to be reconciled. 
Fourth, perhaps a U form is found only for 'evaluative' measures of well-being, and those do not do justice to the complexity of human feelings? Large-scale data sets on experiential or eudemonic measures are rare; more research is needed here. Nevertheless, the Appendix shows in Table A1 that, for a question in the United Kingdom for Worthwhileness of Life, there is again a U-shaped pattern.

Fifth, perhaps the putative midlife low is due to cohort effects? However, it is not easy to see why cohort effects would work in such a similar way in different countries and time periods, and there is other evidence, including some longitudinal, against any simple version of such an explanation. Moreover, any such cohort effects would themselves presumably be important to document and understand.

\section{$\underline{\text { 4. Conclusions }}$}

There is much evidence, in Figures 1 to 6 , that humans experience a midlife psychological 'low'. The decline in well-being is apparently substantial and not minor (see the notes below each Figure, which compare to the coefficients on major life events). Our own view is that these kinds of plots of happiness and life satisfaction should be shown -- with a discussion of appropriate caveats -- to all young psychologists and economists. However, in the interests of scientific completeness, it is important to note exceptions to this conclusion; the paper documents two cases out of seven where if all controls are omitted the dip is not found. Finally, the Appendix offers evidence of a U shape for a measure of 'worthwhileness of life', so the idea of a midlife low does not rest solely on happiness or life-satisfaction data.

In the descriptive approach, in which raw data are plotted, five of the seven data sets suggest evidence of a midlife low and some form of U-shape. In the ceteris paribus approach, all seven data sets point to the existence of a midlife low and a U-shaped curve. In this latter case, the regression equations allow for confounding influences -- including education and marriage -- upon happiness and life satisfaction. In this paper, we have studied data up to the 
age of 90. Sample sizes after this point become small, and non-random, and it would presumably not be sensible to believe that human beings tend to be happy in the few years before they die. We are not able to say why the General Social Survey data set is so different, in its raw patterns than the others. After adjustment, it traces out the same kind of U shape as other sources. The important work of Easterlin (2006) and Glenn (2009), which uses the GSS, has had considerable influence, and is often cited by critics of the idea of U-shaped well-being. It therefore seems important for researchers to know that the pattern in the General Social Survey appears to be unrepresentative of most modern data sets.

Much remains to be understood in this intriguing area of quantitative social science one in which Richard Easterlin has been an immense intellectual figure. 


\section{References}

Argyle, M. (2001). The psychology of happiness. London: Routledge, Second edition.

Baird, B., Lucas, R.E. \& Donovan, M.B. (2010). Life satisfaction across the life span: Findings from two nationally representative panel studies. Social Indicators Research, 99, 183203.

Blanchflower, D.G., \& Oswald, A.J. (2009). The U-shape without controls: A response to Glenn. Social Science \& Medicine, 69, 486-488.

Blanchflower, D.G., \& Oswald, A.J. (2008). Is well-being U-shaped over the life cycle? Social Science \& Medicine, 66, 1733-1749.

Carstensen, L.L., Turan, B., Scheibe, S., Ram, R., Ersnser-Hershfield, H., Samanez-Larkin, G.R., Brooks, K.P., \& Nesselroade, J.R. (2011). Emotional experience improves with age: Evidence based on over 10 years of experience sampling. Psychology and Aging, $26,21-33$

Charles, S.T., Reynolds, C.A., \& Gatz, M. (2001). Age-related differences and change in positive and negative affect over 23 years. Journal of Personality and Social Psychology, $80,136-151$

Cheng, T., Powdthavee, N., \& Oswald, A.J. (2017). Longitudinal evidence for a midlife nadir: Result from four data sets. Economic Journal, 127, 126-142.

Diener, E., Suh, E.M., Lucas, R.E., \& Smith, H.L. (1999). Subjective well-being: Three decades of progress. Psychological Bulletin, 125(2), 276-302.

Easterlin, R.A. (2003). Explaining happiness. Proceedings of the National Academy of Sciences, 100, 11176-11183.

Easterlin, R.A. (2006). Life cycle happiness and its sources: Intersections of psychology, economics and demography. Journal of Economic Psychology, 27, 463-482. 
Frey, B.S., \& Stutzer, A. (2002). Happiness and economics. Princeton: Princeton University Press.

Frijters, P., \& Beaton, T. (2012). The mystery of the U-shaped relationship between happiness and age. Journal of Economic Behavior \& Organization, 82, 525-542.

Galambos, N.L., Fang, S., Krahn, H.J., Johnson, M.D., \& Lachman, M.E. (2015). Up, not down: The age curve in happiness from early adulthood to midlife in two longitudinal studies. Developmental Psychology, 51, 1664-1671.

Gerstorf, D., Ram, N., Mayraz, G., Hidajat, M., Lindenberger, U., Wagner, G.G., \& Schupp, J. (2010). Late life decline in well-being across adulthood in Germany, the United Kingdom and the United States: Something is seriously wrong at the end of life. Psychology \& Aging, 25, 477-485.

Glenn, N.D. (2009). Is the apparent U-shape of well-being over the life course a result of inappropriate use of control variables? A commentary on Blanchflower and Oswald, Social Science and Medicine, 69, 481-485.

Graham, C., \& Pozuelo, J.R. (2017). Happiness, stress, and age: How the U curve varies across people and places. Journal of Population Economics, 30, 225-264.

Hellevik, O. (2017). The U-shaped age-happiness relationship: real or methodological artifact? Quality \& Quantity, 51, 177-197.

Helliwell, J., \& Grover, S. (2014). How's life at home? New evidence on marriage and the set point for happiness. NBER paper, \#20794.

Hudson, N.W., Lucas, R.E. \& Donellan, M.B. (2016). Getting older, feeling less? A crosssectional and longitudinal investigation of developmental patterns in experiential wellbeing. Psychology and Aging, 31, 847-861.

Lachman, M.E. (2015). Mind the gap in the middle: A call to study midlife. Research in Human Development, 12, 327-334. 
Mroczek, D.K., \& Kolanz, C.M. (1998). The effect of age on positive and negative affect: A developmental perspective on happiness. Journal of Personality and Social Psychology, $75,1333-1349$.

Mroczek, D.K., \& Spiro, A. (2005). Change in life satisfaction during adulthood: Findings from the Veterans Affairs Normative Aging study. Journal of Personality and Social Psychology, 88, 189-202.

Schwandt, H. (2016). Unmet aspirations as an explanation for the age U-shape in well-being. Journal of Economic Behavior \& Organization, 122, 75-87.

Shields, M.A., \& Wheatley Price, S. (2005). Exploring the economic and social determinants of psychological well-being and perceived social support in England. Journal of the Royal Statistical Society (Series A), 168, 513-537.

Steptoe, A., Deaton, A., \& Stone, A.A. (2015). Subjective wellbeing, health, and ageing. Lancet, 385, 640-648.

Stone, A.A., Schwartz, J.E., Broderick, J.E., \& Deaton, A. (2010). A snapshot of the age distribution of psychological well-being in the United States. Proceedings of the National Academy of Sciences of the USA, 107, 9985-9990.

Ulloa, B.F.L., Moller, V. \& Sousa-Poza, A. (2013). How does subjective well-being evolve with age? A literature review. Journal of Population Ageing, 6, 227-246.

Weiss, A., King, J.E., Inoue-Murayam, M., Matsuzama, T. \& Oswald, A.J. (2012). Evidence for a midlife crisis in great apes consistent with the U-shape in human well-being, Proceedings of the National Academy of Scences U S A, 109, 19949-19952.

Wunder, C., Wiencierz, A., Schwarze, J. \& Küchenhoff, H. (2013). Well-being over the life span: Semiparametric evidence from British and German longitudinal data. Review of Economics and Statistics, 95, 154-167. 
Figure 1. Life Satisfaction Polynomial in Understanding Society ONS Data (United Kingdom; 416,000 observations). Years 2011-2015.

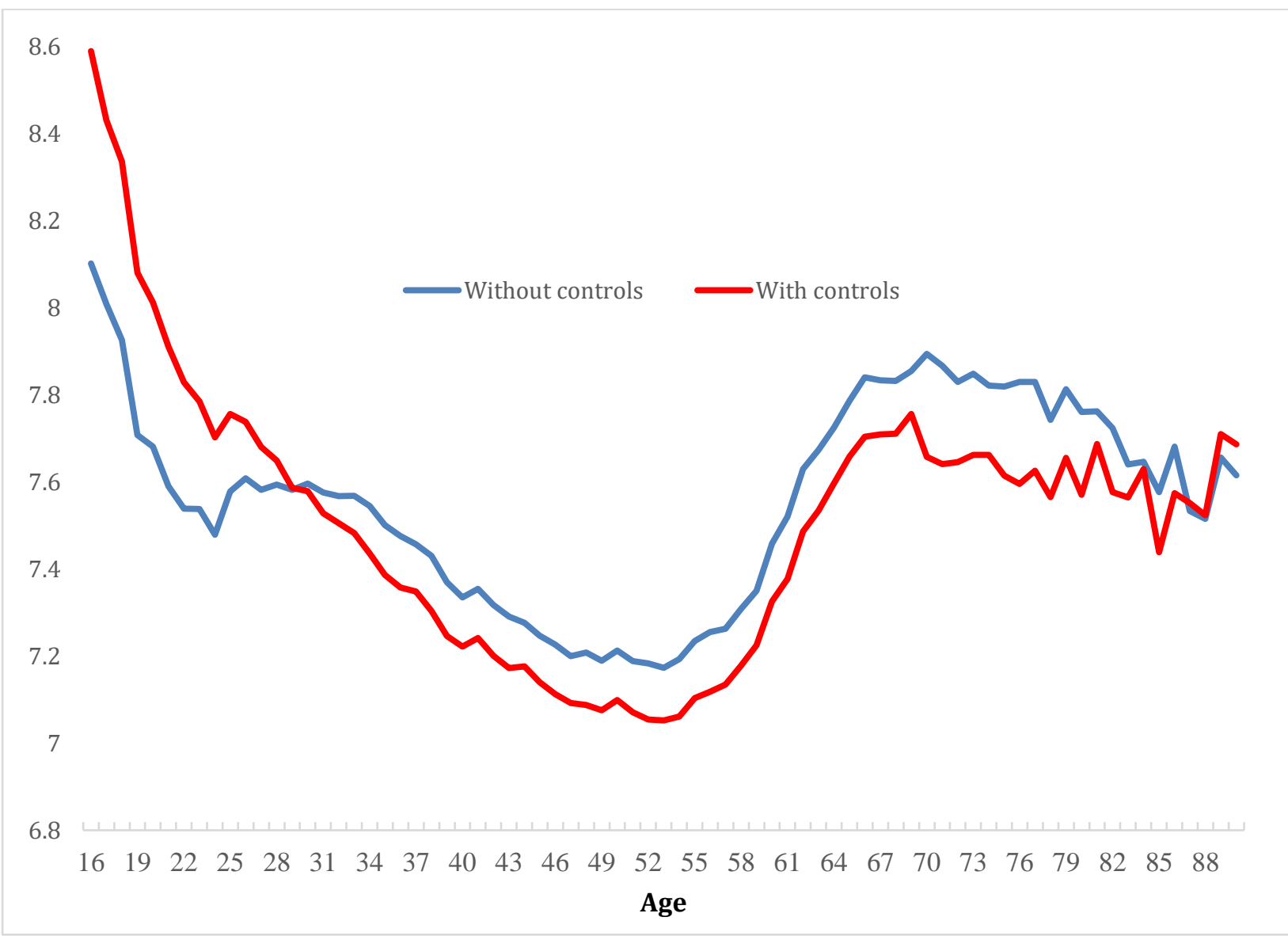

This figure is based on data using the question "Overall, how satisfied are you with your life nowadays?" scored from zero to 10 . To aid in understanding the size of the age effect, the coefficients on marital separation and unemployment in a life-satisfaction equation here are approximately -0.3 and -0.8 .

The figure is constructed by estimating a regression equation with approximately 74 separate age dummy variables. These curves are plots of the age coefficients. Because of the large sample sizes, levels of statistical significance in the paper are high, so for clarity the confidence intervals here, and later, are left off the paper's figures; they are available upon request. 
Figure 2. Life Satisfaction Polynomial in BRFSS Data (USA; 427,000 observations). Year 2010 .

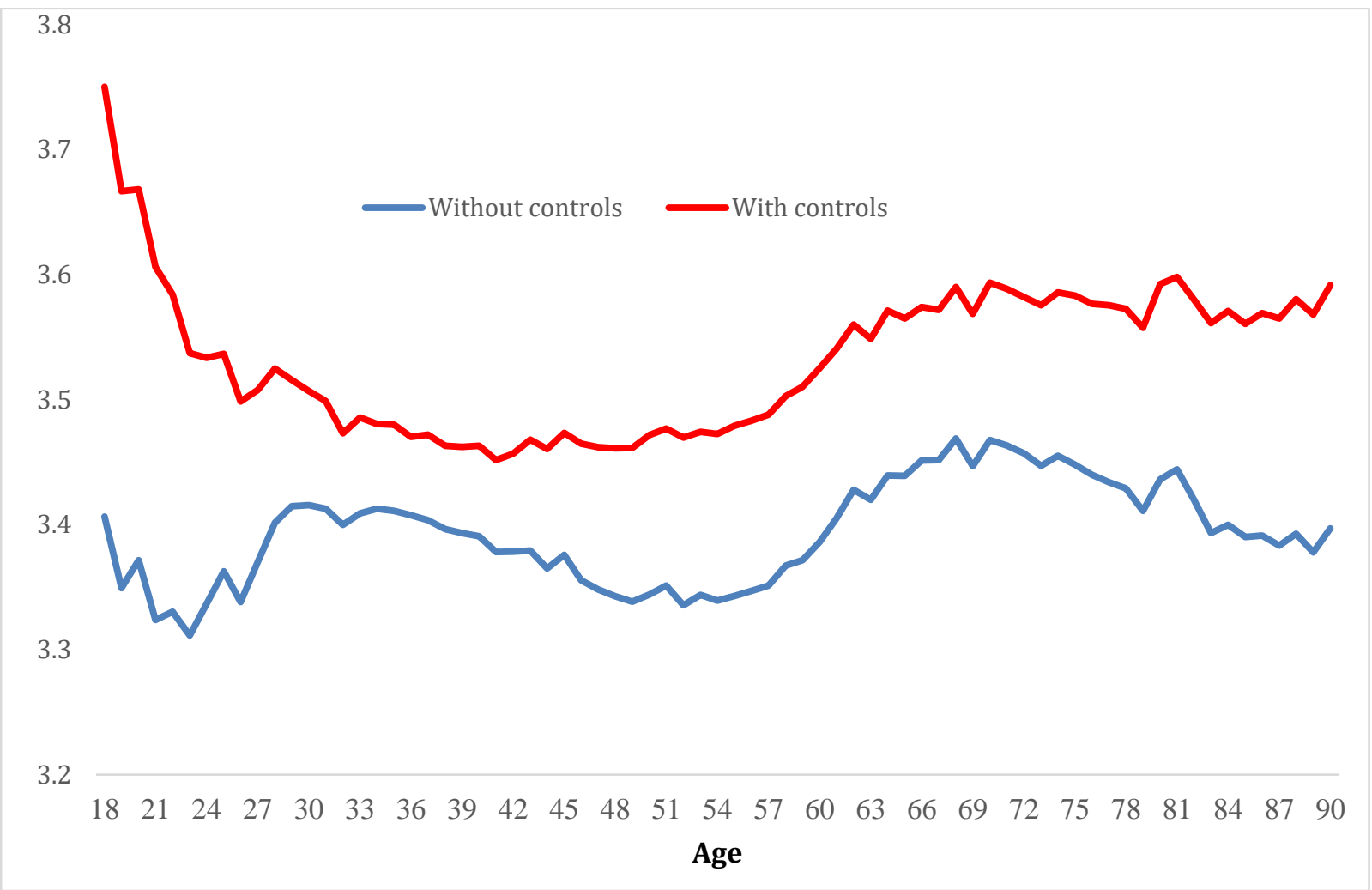

This figure is based on data using the question "In general, how satisfied are you with your life? Very dissatisfied, ...., very satisfied." scored from 1 to 4 . To aid in understanding the size of the age effect, the coefficients on marital separation and unemployment in a lifesatisfaction equation here are approximately -0.3 and -0.3 . 
Figure 3. Life Satisfaction Polynomial in Eurobarometer Data (36 nations; 32,000 observations). Year 2016.

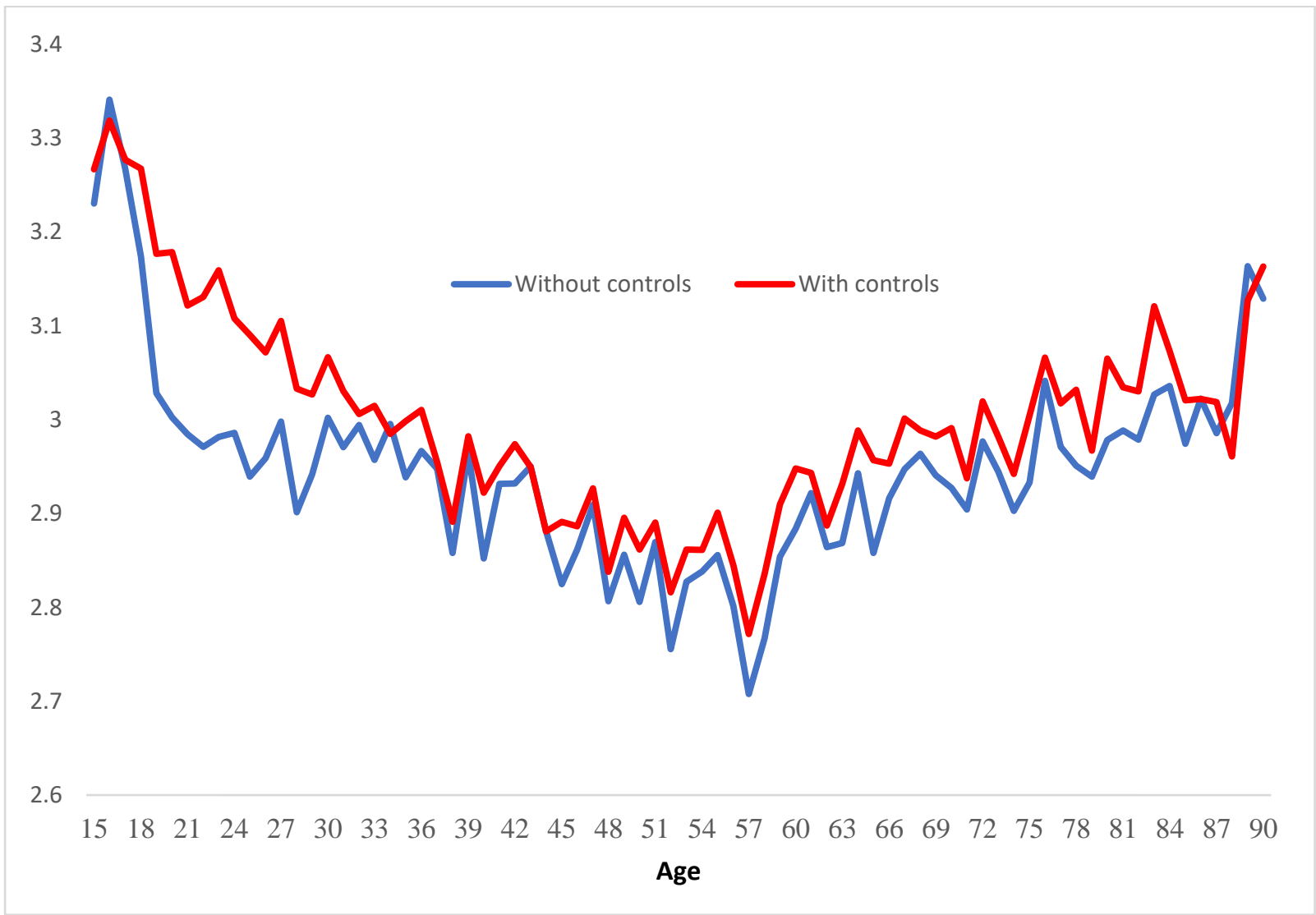

This figure is based on data using the question "On the whole, are you very satisfied, fairly satisfied, not very satisfied,or not at all satisfied with the life you lead?" scored from 1 to 4. To aid in understanding the size of the age effect, the coefficients on marital separation and unemployment in a life-satisfaction equation here are approximately -0.2 and -0.3 . 
Figure 4. Life Satisfaction Polynomial in ESS Data (32 European nations; 316,000 observations). Years 2002-2014.

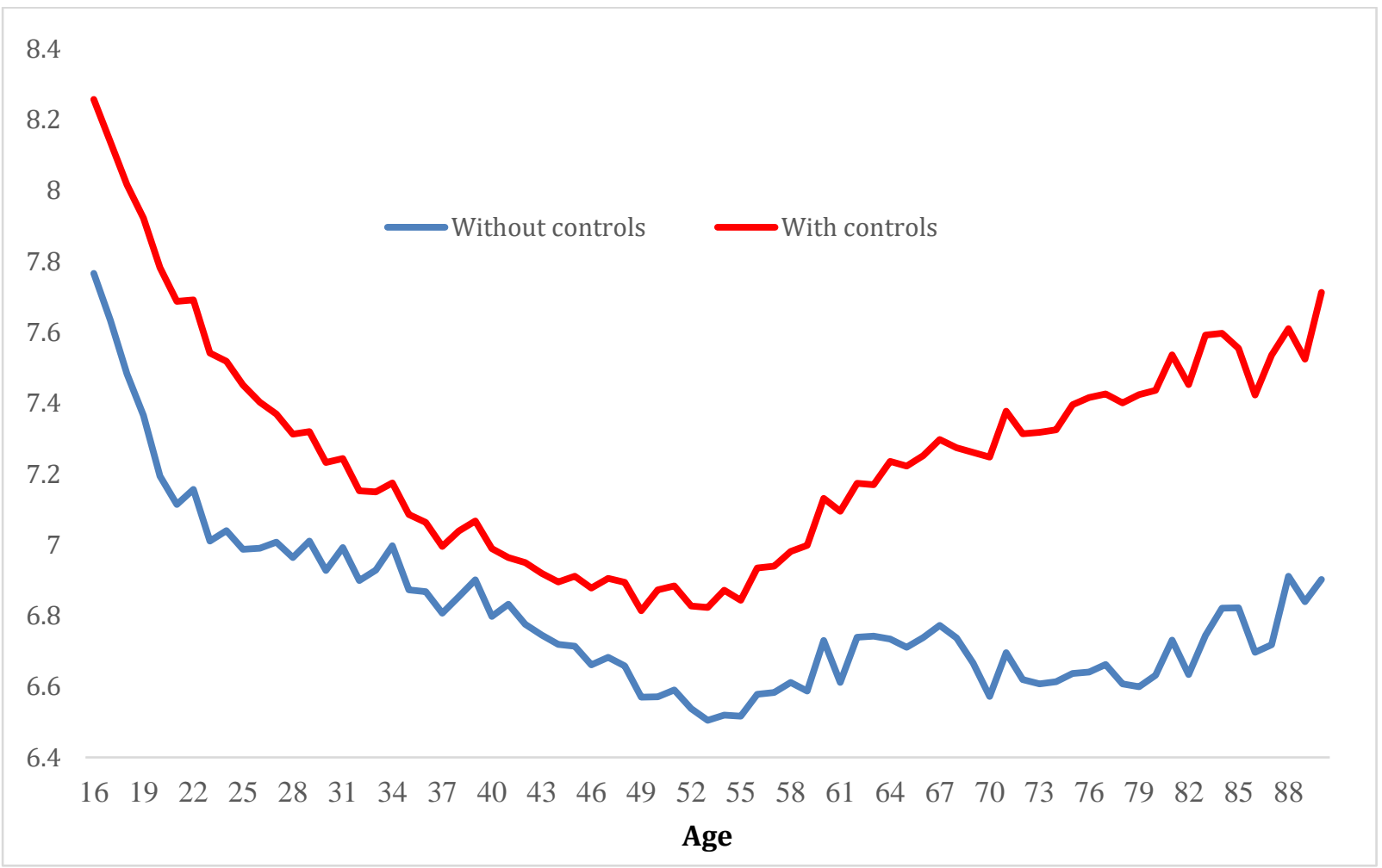

This figure is based on data using the question "All things considered, how satisfied are you with your life as a whole nowadays? Extremely dissatisfied, ....,extremely satisfied." scored from zero to 10. To aid in understanding the size of the age effect, the coefficients on marital separation and unemployment in a life-satisfaction equation here are approximately -1.0 and 0.6 . 
Figure 5. Happiness Polynomial in ISSP Data (41 nations; 59,000 observations). Year 2012.

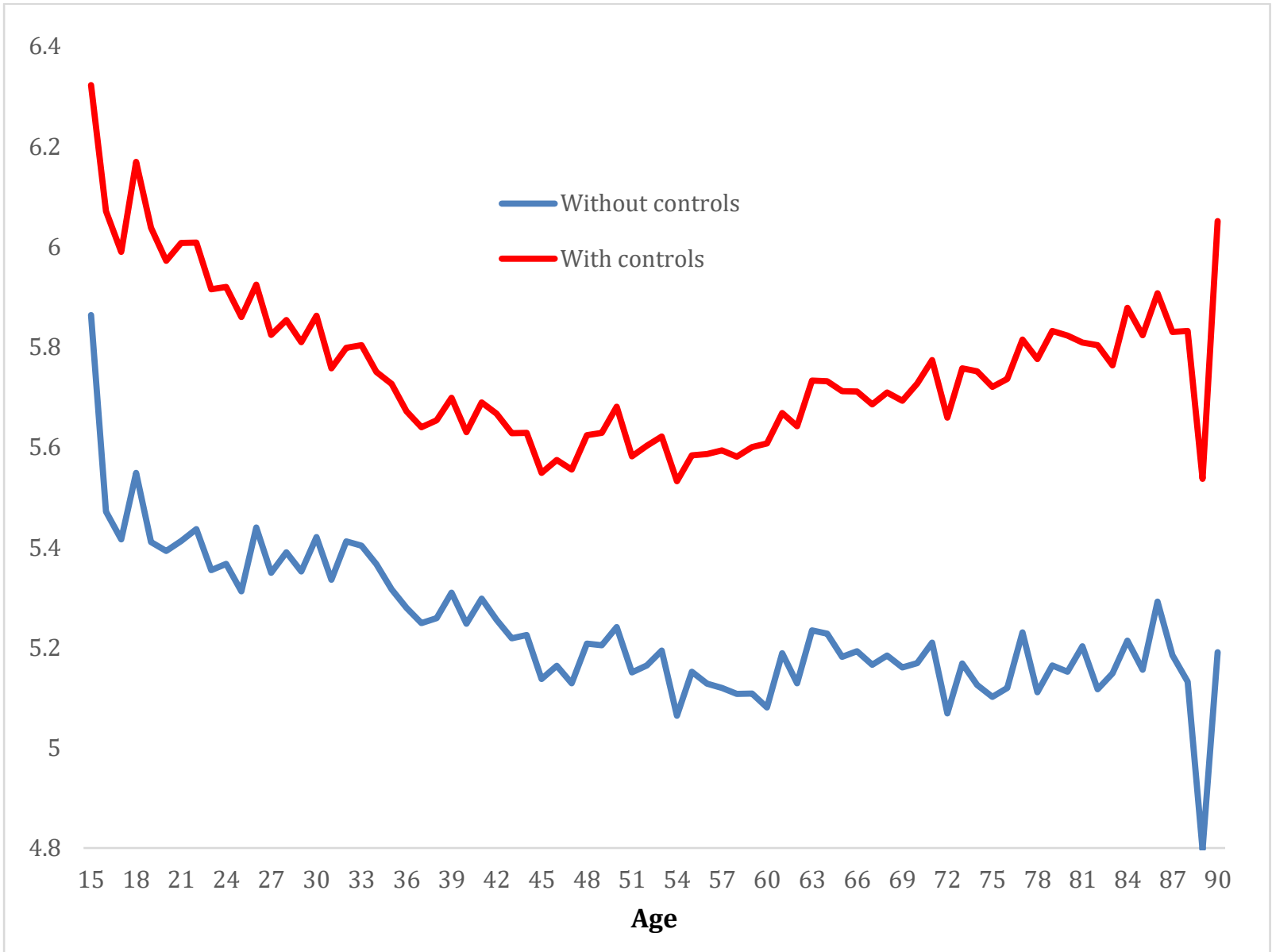

This figure is based on data using the question "If you were to consider your life in general, how happy or unhappy would you say you are, on the whole? Completely happy,...., fairly unhappy" scored from zero to 5. To aid in understanding the size of the age effect, the coefficients on marital separation and unemployment in a happiness equation here are approximately -0.5 and -0.5 . 
Figure 6. Happiness Polynomial in the GSS Data (USA; 54,000 observations). Years 1972-2014.

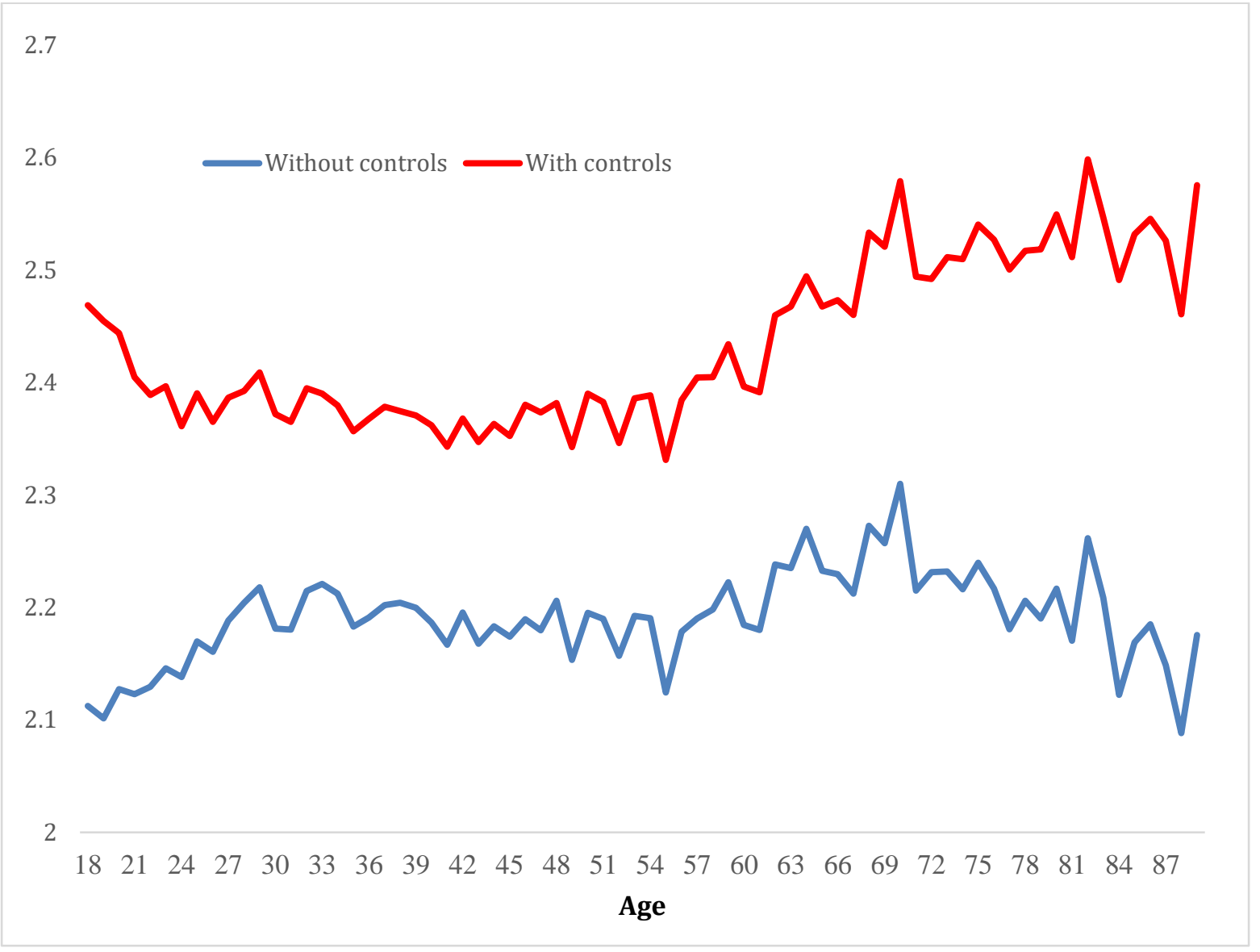

This figure is based on data using the question "Taken all together, how would you say things are these days - would you say that you are very happy, pretty happy, or not too happy?" scored from 1 to 3 . To aid in understanding the size of the age effect, the coefficients on marital separation and unemployment in a happiness equation here are approximately -0.3 and -0.4 . 
Figure 7. Life Satisfaction Polynomial in the Latino Barometer Data (18 nations; 43,000 observations). Years 2013 and 2015 pooled.

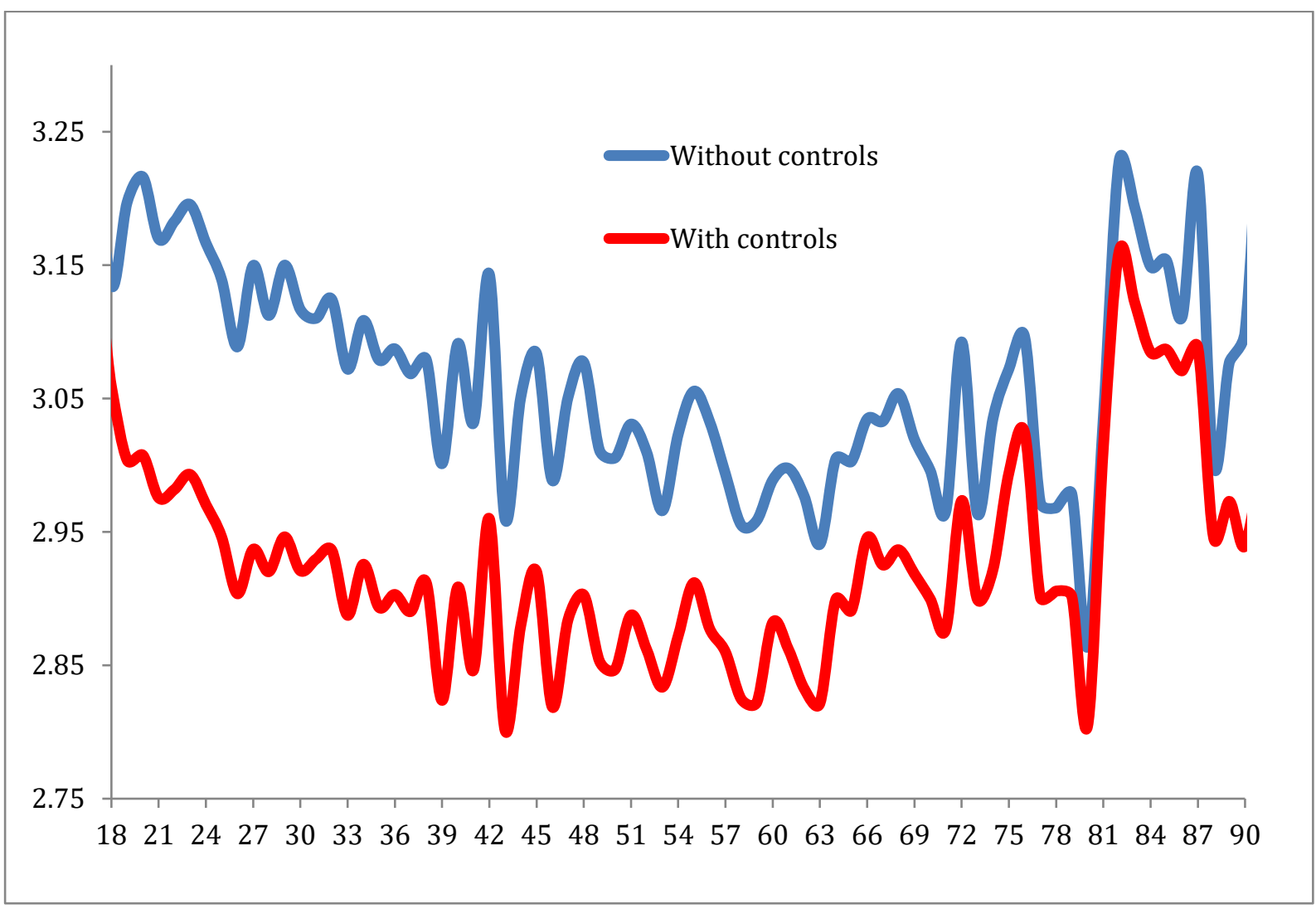

This figure is based on data using the question "Generally speaking, would you say you are satisfied with your life?" scored from 1 to 4 . To aid in understanding the size of the age effect, the coefficients on marital separation and unemployment in a happiness equation here are approximately -0.1 and -0.2 . 
APPENDIX MATERIAL

Figure A1. Worthwhileness-of-Life Polynomial in Understanding-Society ONS Data (United Kingdom; 416,000 observations) Years 2011-2015

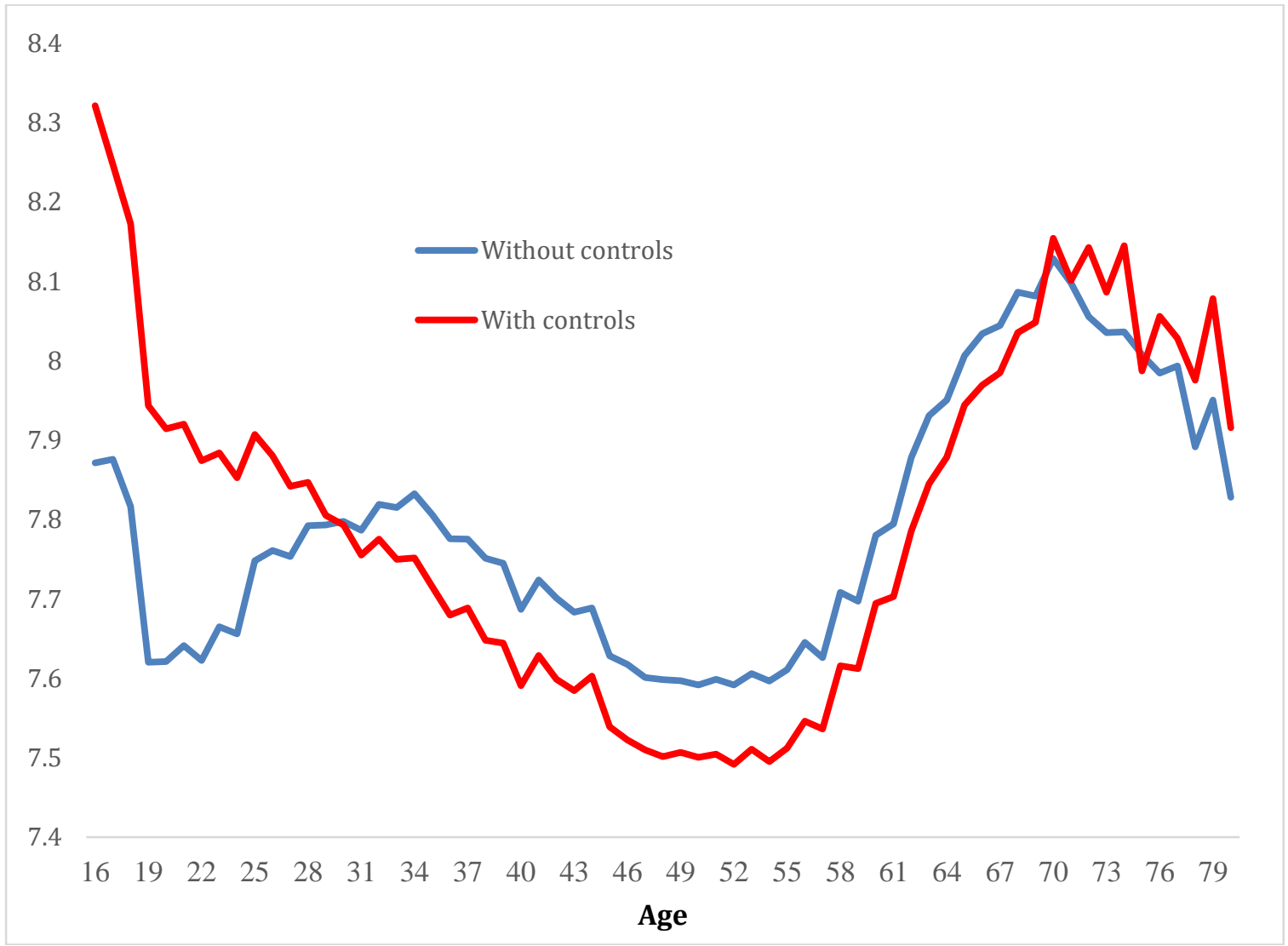

This figure is based on data using the question "Overall, to what extent do you feel the things you do in your life are worthwhile?" scored from zero to 10. 